\title{
Cellulose nanomaterials: size and surface influence on the thermal and rheological behavior
}

\author{
Marcos Mariano ${ }^{1,2 *}$, Nadia El Kissi ${ }^{2}$ and Alain Dufresne ${ }^{1}$ \\ ${ }^{1}$ University Grenoble Alpes, National Center for Scientific Research - CNRS, Grenoble INP, LGP2, \\ Grenoble, France \\ ${ }^{2}$ University Grenoble Alpes, National Center for Scientific Research - CNRS, Grenoble INP, LRP, \\ Grenoble, France \\ *marcos.mariano@lgp2.grenoble-inp.fr
}

\begin{abstract}
Cellulose nanocrystals (CNC) and nanofibrils (CNF) were obtained by acid hydrolyzis and mechanical treatment, respectively, of cellulosic fibers from paper. Additionally, surface modification was performed for CNC by neutralization $(\mathrm{NaOH})$ and oxidation (TEMPO). The thermal stability, surface properties and rheological behavior of these nanomaterials were compared. A clear difference in CNC surface was found upon neutralization and oxidation treatments, leading to distinct thermal behaviors. Optical and rheological properties were found to be predominantly by the particles size, being strongly affected by inertial effects.
\end{abstract}

Keywords: cellulose nanocrystals, cellulose nanofibrils, thermal stability, rheology.

\section{Introduction}

The use of natural fibers as raw materials to produce biocomposites is a tendency that fits perfectly the actual society needs. A combination of extensive research and recent technological advances allows the use of nanomaterials in new renewable material development. As the most abundant polymer on earth, cellulose studies goes toward the described scenario. Its fibers are now used to produce new composites with different matrix by different processing techniques ${ }^{[1-4]}$. The use of its natural structure to produce nanomaterials was developed during the last two decades and shows promising results. Many initial difficulties are now overcame and advances have been made concerning their obtention, surface modification and processing ${ }^{[5]}$.

Derivated from natural fibers, bacteria or algaes, cellulose nanomaterials are versatiles materials that are now applied in nanopapers ${ }^{[6]}$, hydrogels ${ }^{[7]}$, $\operatorname{composites}^{[8]}$, electronic ${ }^{[9]}$, biomedicine ${ }^{[10]}$, etc. Being a versatile material, cellulose processing can be adjusted to provide different materials as, for example, cellulose nanofibril (CNF) or cellulose nanocrystal (CNC). The first one can be obtained by mechanical defibrillation or enzymatic treatment of cellulose fibers ${ }^{[11]}$, which leads to individualization of cellulose nanofibers that compose the intrisic structure of the polymer. The second one is obtained by the isolation of crystalline domains present in the structure by hydrolysis of amorphous part using acid or enzymatic steps ${ }^{[12,13]}$.

Concerning its actual applications, CNF is used in hydrogels and high technology papers. During its production by mechanical defibrillation, it is common to use TEMPO (2,2,6,6-tetramethyl-1-piperidinyloxy radical) oxidation as pretreatment. This step facilitates the fiber individualization, being a way to save energy and make greener process.

$\mathrm{CNC}$ is normally used in nanocomposite production to provide better barrier or mechanical properties ${ }^{[14,15]}$.
To ensure the quality and explore the complete potential of this nanoparticle, its surface can be modified to improve the filler-matrix compatibility or increase the thermal stability. In the case of molecule grafting to nanocrystal surface, also a TEMPO modification has became a common process used as first stage to allow chemical modification ${ }^{[16]}$. Aiming in the production of nanocomposites at high temperatures, the CNC surface also can be modified. The presence of sulfate groups attached to its surface after hydrolysis can decrease its thermal stability. A dessulfation process can be performed by the addition of a diluted $\mathrm{NaOH}$ solution into the suspension. In this case, the thermal degradation seems to be postponed ${ }^{[17]}$.

In this study, these different materials were obtained from paper using different methodologies. Cellulose nanocrystals were obtained by acid hydrolyzis and neutralized (CNC-n) or oxidized (CNC-t) using TEMPO reagent. The nanocrystal properties were compared to cellulose nanofibrils $(\mathrm{CNF})$ obtained by mechanical treatment. Aiming to compare the properties of these different materials, obtained from the same source, the nanoparticles were characterized by different techniques.

\section{Materials and Methods}

\subsection{Materials}

The paper used in this study was purchased from Whatman ${ }^{\circledR} . \mathrm{NaOH}$ and sulfuric acid were obtained from Sigma-Aldrich.

\subsection{Methods}

In this section, the experimental process used during the preparation of the nanomaterials will be described. An illustrative scheme of the obtained materials is reported in Figure 1. 


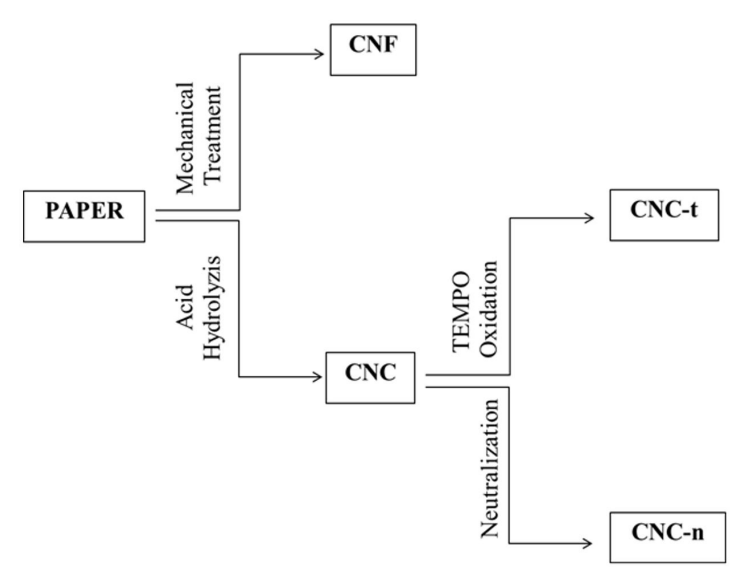

Figure 1. Illustrative scheme of the preparation methods and obtained materials.

\subsubsection{Nanomaterials obtention}

Nanocrystal preparation. Firstly, the cellulose fibers obtained from paper were maintained under agitation in a $2 \% \mathrm{NaOH}$ solution for 6 hours at $25^{\circ} \mathrm{C}$ and after that it was washed until neutral $\mathrm{pH}$ and dried in ambient conditions. For hydrolysis of bleached fibers, $400 \mathrm{~mL}$ of a sulfuric acid solution $\left(65 \mathrm{wt} \%\right.$ ) was heated up to $45^{\circ} \mathrm{C}$ and $20 \mathrm{~g}$ of fibers was suspended in the solution under a strong mechanical stirring for $45 \mathrm{~min}$. After the desired time, the reaction was stopped with the addition of some ice cubes and the suspension was centrifuged in cycles of 10 minutes under a centrifuge force of $1373.6 \mathrm{G}$. After each cycle the acid supernatant was discarded and replaced by distilled water, this process was repeated a few times to increase the $\mathrm{pH}$ of the suspension. The resultant water suspension was dialyzed with a cellulose membrane against distilled water until its $\mathrm{pH}$ was around 5. Some drops of chloroform were added to avoid any bacterial proliferation and the suspension was stored under refrigeration.

Particle neutralization. After its preparation and dialysis, the $\mathrm{pH}$ of part of the cellulose nanocrystal suspension was adjusted to 9 using a diluted $\mathrm{NaOH}$ solution. This suspension was kept under agitation for $24 \mathrm{~h}$ and again dialysed until neutral $\mathrm{pH}$.

Tempo oxidation. The oxidation of hydroxyl groups by TEMPO reagent was develop by Nooy ${ }^{[18]}$ and is broadly used in the oxidation of cellulosic materials. Here, the generic procedure used for the modification of cellulose nanocrystals and cellulose fibers (pretreatment) is described. In an ice bath, a weight of $4 \mathrm{~g}$ of cellulose material was suspended in $400 \mathrm{~mL}$ of water to obtain a $1 \mathrm{wt} \%$ suspension. The suspension was homogenized with a strong mechanical agitation and $0.4 \mathrm{~g}$ of $\mathrm{NaBr}$ and $0.1 \mathrm{~g}$ of 2,2,6,6-tetramethylpiperidine (TEMPO) were added to the suspension. This agitation was maintained for almost $20 \mathrm{~min}$, to ensure a complete dissolution of the reagents, and slowly $10 \mathrm{~mL}$ of a $12 \%$ aqueous $\mathrm{NaOCl}^{-}$solution was added to the reaction medium. The $\mathrm{pH}$ should be kept between 10 and 11 with an eventual addition of diluted $\mathrm{NaOH}$ solution. After 2 hours, $10 \mathrm{~mL}$ of ethanol was added to the medium and the $\mathrm{pH}$ adjusted to 7 with a diluted acid solution. For the cellulose fibers, filtration and washing with distilled water was performed. $\mathrm{CNC}$ was dialysed against distilled water for several days.

Nanofibril preparation. The previrous oxidized fibers were resuspended in water and the concentration was adjusted to $1 \mathrm{wt} \%$. This suspension was treated with a Masuko Supermass colloider grinder for 60 passes.

\subsubsection{Materials characterization}

Atomic Force Microscopy (AFM). The images were obtained on a NanoscopelIIa microscope from Veeco Instruments. A drop of a diluted aqueous $\mathrm{CNC}$ suspension with $0.01 \mathrm{wt} \%$ concentration was deposited on a mica substrate and dried. It was imaged in tapping mode with a Silicon cantilever. The nanoparticle dimensions were estimated from 50 measurements analyzed using the associated Nanoscope software.

Zeta Potential $(\xi)$. Nano particle suspensions with concentration around $0.01 \mathrm{wt} \%$ were analyzed on an equipment model DTS0230 from Malvern Instruments. To avoid the effects of ionic strength and $\mathrm{pH}$ during measurements, all the concentrated solutions were diluted in an aqueous standard solution with $\mathrm{pH} 10$ and $180 \mu \mathrm{S} / \mathrm{cm}$ conductivity. This solution was prepared by the addition of diluted $\mathrm{NaOH}$ solution and solid $\mathrm{NaCl}$ into distilled water.

Contact Angle (CA). Films $0.1 \pm 0.01 \mathrm{~mm}$ thick were prepared by casting/evaporation and analyzed with an Attension Theta contact angle meter equipment by using water as liquid. The samples were cast in a Teflon mold to ensure a smooth surface and the contact angle was measured during $120 \mathrm{~s}$. The final angle value before surface deformation was used as reference.

Fourrier Transform Infrared Spectroscopy (FTIR). ATR mode measurements were performed on a FTIR Perkin-Elmer Spectrum One equipment between 600 and $4000 \mathrm{~cm}^{-1}$ in $4 \mathrm{~cm}^{-1}$ intervals. All the analyses were carried out using films casted and dried at room temperature.

Thermogravimetric Analysis (TGA). The analysis was carried out under Air atmosphere using Perkin-Elmer TGA-6 equipment. The sample heating was performed from room temperature up to $600^{\circ} \mathrm{C}$ with a heating of $10^{\circ} \mathrm{C} \cdot \mathrm{min}^{-1}$.

Rheological Measurements. The rheological behavior of the dispersions was characterized with a DHR-3 equipment from TA Instruments. A cone $\left(2^{\circ}, 50 \mathrm{~mm}\right)$ - plate $(50 \mathrm{~mm})$ geometry was used to study the dilute suspensions in flow and oscillatory modes at $20^{\circ} \mathrm{C}$.

Degree of polymerization. The samples viscosity were measured by the TAPPI methodology T230m08 and the D.P. estimated by the Equation 1.

$$
D . P .=-449.6+598.4 \ln [\eta]+118.02(\ln [\eta])^{2}
$$

$\mathrm{X}$-ray diffraction. XRD measurements for the samples were recorded on a Philips PW $1720 \mathrm{X}$-ray generator operated at $45 \mathrm{kV}$ and $40 \mathrm{~mA}$ in a Bragg-Brentano geometry. The $2 \theta$ range was from $5^{\circ}$ to $65^{\circ}$ using a fixed time mode with a step interval of $0.066^{\circ}$ and $\mathrm{Cu}$ Ka radiation $(\mathrm{k}=1.5418 \AA)$. The crystallinity index (C.I.) was obtained by the relation between crystalline phase $2 \theta=22^{\circ}$ and amorphous phase on $2 \theta=18.5^{\circ}$ following the Equation 2 . 


$$
\text { C.I. }(\%)=\frac{I 200-I a m}{I 200} \times 100
$$

Samples nomemclature and other obtained properties are on Table 1.

\section{Results and Discussion}

\subsection{Atomic force microscopy and surface properties}

Different procedures were applied to obtain cellulose nanomaterials with distinct characteristics. The morphology of the nanoparticles resulting from the acid and mechanical treatments is shown in Figure 2.

For the acid hydrolyzed material $(\mathrm{CNC})$ rod-like structure can be observed (Figures $2 \mathrm{a}$ and $2 \mathrm{~b}$ ). These nanometric rods are the non-hydrolyzed crystalline domains present in the hierarchical structure of cellulose. After post-treatment performed on the pristine $\mathrm{CNC}$, the dimentions (Table 1) of CNC-t and CNC-n seem to be basically the same, no visible sign of degradation caused by the basic of oxidative treatment at the surface could be found. In both cases, the particle dimentions are in agreement with dimentions reported in literature, being similar to the estimated size of nanocrystals obtained from hardwood ${ }^{[19]}$.

Figure 2c shows CNF particles. These particles have very different characteristics when compared to the previous one. Longer and more flexible than CNC nanorods, CNF occurs as particles with higher aspect ratio (L/d). This characteristicis are in agreement with the expected structure of particles obtained after mechanical or enzymatic treatment. In this process, hydrolyzis of the amorphous part of cellulose does not occur, with the isolation of individual fibrils being the principal objective. From the AFM image it is possible to observe some microscale fibers. Probably, the mechanical treatment was not able to provide particles with a narrow size distribution, were individual nanofibers are completely isolated. However, the presence of fibers with a nanometric diameter (around $6 \mathrm{~nm}$ ) is predominant compared to bigger agglomerates.

Besides its dimentions, the particle surface also are quite different. The $\xi$ measurements shows that the CNC-n present a less negative surface charge. This is probably a consequence of the neutralization stage, where the $\mathrm{NaOH}$ solution can neutralize acid residues and the negative sulfate groups presents at the nanoparticle surface. As a consequence, it means that this suspension is less stable against coalescence than the others. CNC-t and CNF have similar $\xi$ values. It can suggest that the number of oxidized $-\mathrm{OH}$ groups during the TEMPO reaction was not so different although the different surface areas avalaible during the reaction.

\subsection{Infrared spectroscopy}

Figure 3a shows the FTIR spectrafor the different nanoparticles. The figure also shows the spectrum of pristine cellulose fibers (CP) to be used as reference. Firstly, all the curves show typical peaks of cellulose, i.e. C-H $\left(2900,1300 \mathrm{~cm}^{-1}\right), \mathrm{C}-\mathrm{C}\left(1600 \mathrm{~cm}^{-1}\right), \mathrm{C}-\mathrm{O}$ $\left(3330,1000 \mathrm{~cm}^{-1}\right), \mathrm{C}-\mathrm{O}-\mathrm{C}\left(1150 \mathrm{~cm}^{-1}\right)$ and O-H $\left(3330 \mathrm{~cm}^{-1}\right)$ bands. However, besides the homogeneous distribution of size and no sign of particle degradation, the FTIR analyzis shows some modifications in CNC structure. Probably, these modifications occur at the surface of the nanorods during the post-treatment of oxidation or neutralization. Surprisingly, the spectra for CNC-n and CNC-t are quite
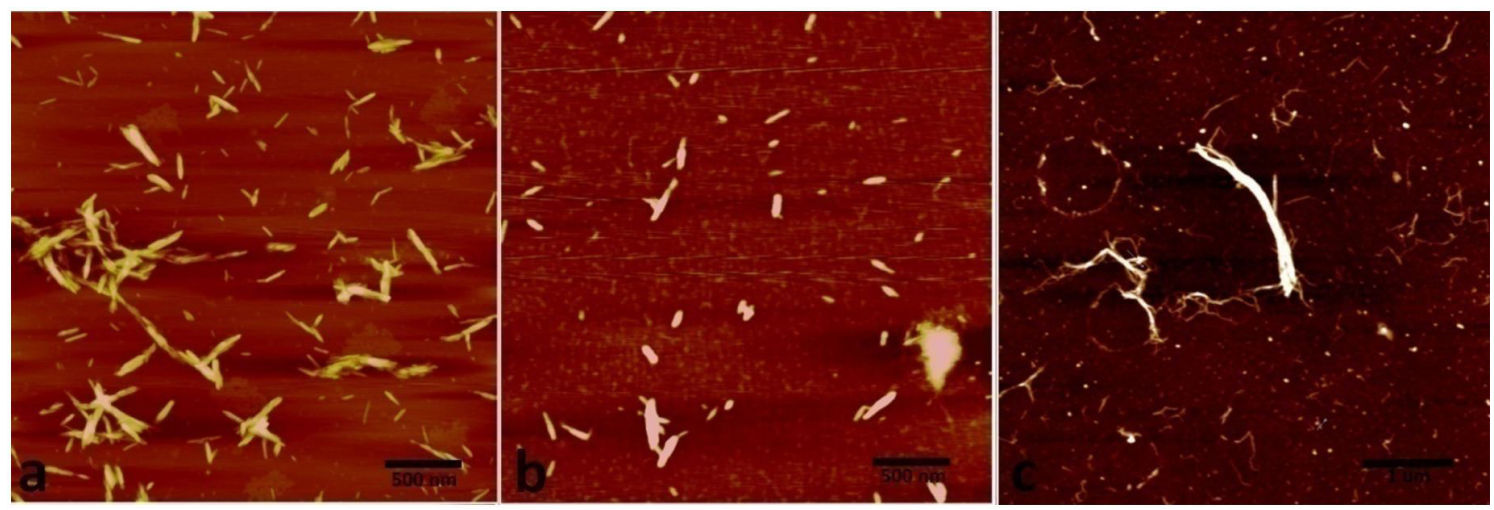

Figure 2. AFM images of (a) CNC-n, (b) CNC-t and (c) CNF.

Table 1. Samples nomenclature and general properties.

\begin{tabular}{lcccccccc}
\hline \multicolumn{1}{c}{ Sample } & Nomenclature & D.P. & $\mathbf{L ~ ( n m )}$ & $\mathbf{D}(\mathbf{n m})$ & $\mathbf{L} / \mathbf{D}$ & $\xi(\mathbf{m V})$ & $\begin{array}{c}\text { Contact } \\
\text { Angle }\left({ }^{\circ}\right)\end{array}$ & C.I. \\
\hline $\begin{array}{l}\text { Paper } \\
\text { NaOH-neutralized Cellulose }\end{array}$ & CP & 2598 & - & - & - & - & - & - \\
$\begin{array}{l}\text { Nanocrystals } \\
\text { TEMPO-oxidized Cellulose }\end{array}$ & CNC-t & 462 & $147 \pm 20$ & $8.5 \pm 2.5$ & 17.3 & -26.9 & 17 & 87 \\
$\begin{array}{l}\text { Nanocrystals } \\
\text { Cellulose Nanofibrils }\end{array}$ & CNF & 475 & $145 \pm 41$ & $8.3 \pm 2.7$ & 17.4 & -32.7 & 33 & 88 \\
\hline
\end{tabular}


similar. The presenceof a $\mathrm{C}=\mathrm{O}$ peak at $1740 \mathrm{~cm}^{-1}$ for $\mathrm{CNC}-\mathrm{t}$ is a consequence of the TEMPO-oxidation, that can oxidize the $\mathrm{C}-\mathrm{O}$ bonds naturally present in the cellulose structure. On CNC-t also is possible to observe a $2840 \mathrm{~cm}^{-1}$ peak, that is normally attributed to $\mathrm{C}-\mathrm{H}$ bonds in alkanes. This peak can corroborate the higher value of contact angle if we assume some surface degradation during the reaction. It seems possible once the C.I. for this sample had a slight decrease when compared to the $\mathrm{CNC}-\mathrm{n}$ sample.

The presence of the same $\mathrm{C}=\mathrm{O}$ signal for $\mathrm{CNC}-\mathrm{n}$ was not expected. In this sample, the neutralization process was supposed to cause just a dessulfation of the nanocrystal surface $^{[17]}$. However, this step seems to also cause an oxidation of the O-H groups to form carbonyl groups, probably resulting in carboxylic acids or aldehydes formation. CNF also presents the $\mathrm{C}=\mathrm{O}$ peak, a consequence of the TEMPO pre-treatment. In this sample it is worth to notice a prominent band at $1600 \mathrm{~cm}^{-1}$, that can be related to a slightly offset $\mathrm{O}-\mathrm{H}$ bending peak of absorbed water $\left(\sim 1620 \mathrm{~cm}^{-1}\right)$ band or a $\mathrm{C}=\mathrm{C}$ aromatic band. In the last case, it can be attributed to some residual hemicelluloses. Once in this sample no acid hydrolysis was performed, the presence of residual oligomers is possible.

Concerning the samples polymorphism, all the samples had shown cellulose I patterns with intense peaks on $2 \theta$ equals to $15^{\circ}(110), 17^{\circ}(110)$ and $23^{\circ}(200)$. However, CNC-n shows a small peak on $2 \theta$ equals to $12^{\circ}(101)$, that is characteristic of cellulose II. It suggests a cellulose conversion (of a small number of chains) from type I $\rightarrow$ II during the neutralization step. Figure $3 \mathrm{~b}$ shows the XRD curves for the CNC-t sample in comparison to CNC-n.

\subsection{Thermal behavior}

As a consequence of the surface modification suggested by FTIR, C.I. and zeta potential (Table 1) values, the particles could show very different properties, once these parameters are critically important to define particle behavior in suspension and its thermal behavior. The thermal stability of the samples was investigated by thermogravimetric analysis. The obtained thermograms are shown in Figure 4 and the related data reported in Table 2.

Firstly, a higher amount of water present in the nanometric samples is observed. This can be explained by the higher surface area of this particles, providing more available $-\mathrm{OH}$ groups with which water molecules can interact. As suggested by contact angle measurements (Table 1) and FTIR, CNC-t is more hydrophobic than other nanocellulosic samples, showing a lower water content.

The thermal behavior and degradation stages of cellulose materials are very well described in literature. While cellulosic fibers tend to degrade in multiple stages due to their heterogeneous composition with presence of macromolecules such as lignin and hemicelluloses, acid hydrolyzed nanocrystals tend to degrade at lower temperatures due to the presence of sulfate groups ${ }^{[20,21]}$. Here, the use of a bleached commercial paper seems to minimize the first phenomena for the CP sample. Nevertheless, it is possible to observe the degradation of cellulose over a very broad temperature range (Figure $4 \mathrm{~b}$ ), being the cellulose maximum degradation peak normally described around $360{ }^{\circ} \mathrm{C}^{[22]}$.

Concerning the nanomaterials (CNC and CNF) the thermal degradation can be distinguish in two groups. In the first one, $\mathrm{CNC}-\mathrm{n}$ seems to have a similar degradation mechanism
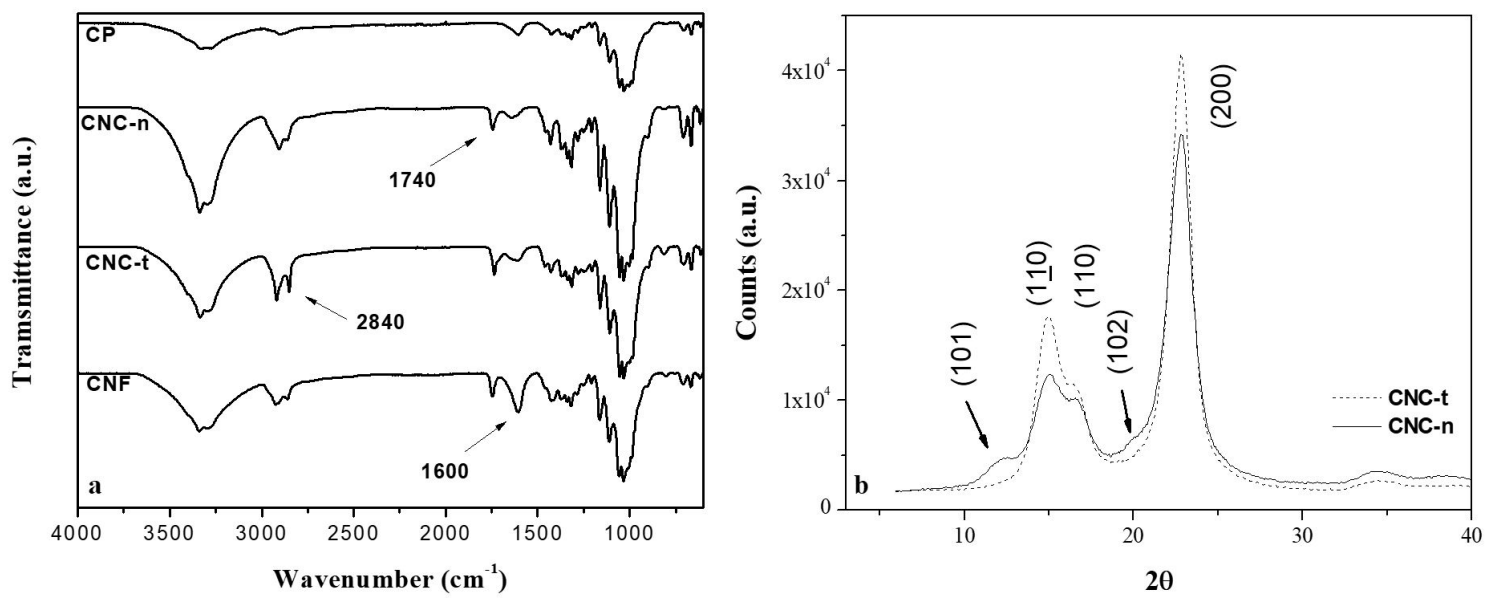

Figure 3. FTIR (a) spectra for paper and nanocellulosic materials and XRD (b) patterns for CNC-t and CNC-n.

Table 2. Thermogravimetric analysis data.

\begin{tabular}{cccccc}
\hline Sample & $\begin{array}{c}\text { Water \% } \\
\left(\text { at 150 }^{\circ} \mathbf{C}\right)\end{array}$ & Degradation Stages & Onset degradation & dTg peak & $\begin{array}{c}\text { Char residue \% at } \\
\mathbf{6 0 0}^{\circ} \mathbf{C}\end{array}$ \\
\hline CP & 4.5 & 2 & 214 & 350 & 11.7 \\
CNC-n & 5.8 & 2 & 235 & 350 & 20.3 \\
CNC-t & 5.0 & 2 & 190 & 315 & 25.2 \\
CNF & 5.8 & 2 & 220 & 315 & 28.8 \\
\hline
\end{tabular}


as CP. These nanoparticles presents a good thermal stability, with a dTG (Figure $4 \mathrm{~b}$ ) in the same temperature range as pristine cellulose $(\mathrm{CP})$, but its degradation occurs within a narrower temperature range. This higher thermal stability is a direct consequence of the neutralization step, that avoids early degradation of the material by removing residual acids and causing dessulfatation of the particle surface ${ }^{[23]}$.

As expected, the molecular weight (expressed in terms of DP, Table 1) of the pristine cellulose was almost six times higher than for other samples. The nanomaterials had present similar values of DP on a range similar to the described by Matsuoka et al. ${ }^{[24]}$ as the length of cellulose crystalline region. However, it seems to not be the major influence on this property since the $\mathrm{CP}$ and $\mathrm{CNC}-\mathrm{n}$ shows similar $\mathrm{dTG}$ values besides its different values of DP.

In the second group, CNC-t and CNF also show similar thermal behavior. In these samples, the presence of two degradation stages is more pronounced than in the first group. These two stages are normally visible on acid hydrolyzed nanocrystals. In fact, it seems to be a consequence of the early degradation of external chains of the particle that accelerates the formation of oligomers that can cause a kind of caramelisation effect in the sample surface that can coat the material core, retarding its degradation. The similar degradation temperatures and dTG for CNC-t and CNF suggests that carboxylic groups can also produce this kind of effect.

For all samples, there is a remarkable increase in char residue when comparing nanomaterials to pristine paper. Is known that the pathway of thermal degradation of the samples seems to be responsible to change the residual content and that parameters such as activation energy, heating rate, temperature of dehydratation and levoglucosan formation can strongly affect the residues content and appearance ${ }^{[25]}$. Besides the normally cited presence of sulfate groups, other surface characteristics also can lead to modify the degradation pathway. For example, an increase on the surface area or presence of grafted groups on cellulose surface also can cause variation on the thermal degradation.

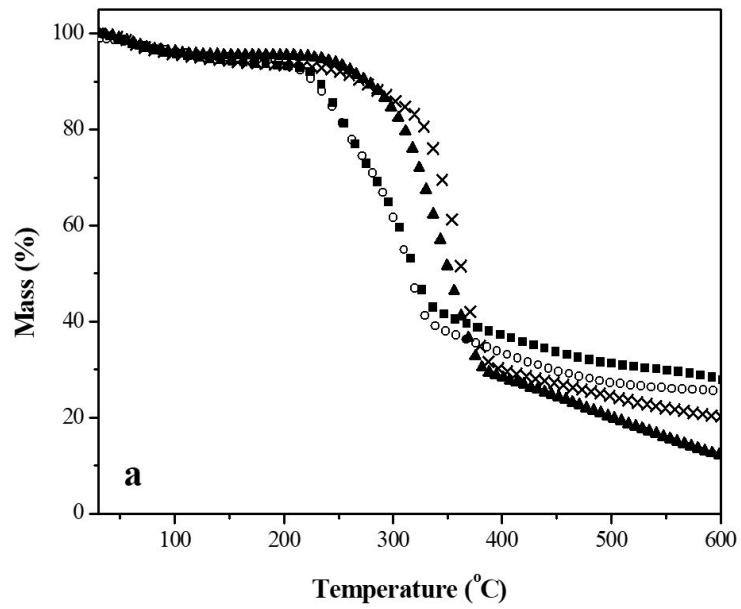

Here, the higher residues content were present on TEMPO-oxidized samples. It occurs due to the easy surface oxidation of the material and is clearly observable by comparison with the other samples (presenting $\mathrm{C}=\mathrm{O}$ or -OH groups, for example). This oxidation seems to accelerate the process of coating the internal cellulose chains. Due to its lower C.I. (Table 1), the core chains of CNF and CNC-t are not so protected from external heat transfer as CNC-n and these samples presents lower dTG values. However, on these two samples the final mechanism seems to occur by a pathway of smaller Ea that leads to the formation of char ${ }^{[24]}$.

\subsection{Optical properties and suspension behavior}

In water suspension, these particles also show different behaviors. The observation of nanoparticles under a polarized light is a way to observe oriented and cristalline structures. Figure 5 shows the presence of birefringence in the nanocrystal samples.

The birefringence of $\mathrm{CNC}$ suspensions can result from two factors: (i) the structural form anisotropyof cellulose nano-domaines (anisotropic refractive index, $\Delta \mathrm{n}$ of 0.05 ) and (ii) a flow anisotropy resulting from alignment of the nanorods (if long enough) under flow. In this study, this alignment was induced by the creation of a shear in the suspension using magnetic stirring. Some studies demonstrated that an imposed shear can produce planar domains of randomly oriented nanoparticles that are aligned or broken with the shear rate variation ${ }^{[26]}$. The level of organization in the nanoparticle suspension is a key factor to its rheological properties and will be discussed in sequence.

This birefringence phenomenon cannot be observed in the CNF system. In addition to its big dimentions (at least in one axis), it was demonstred by Karppinen et al. ${ }^{[26]}$ that CNF have a tendency to entangle (in a reversible way) when submitted to shear, making difficult their alignment with the flow.

\subsection{Flow curves}

According to Bercea and Navard ${ }^{[27]}$, the critical concentrations for a regime transition between diluted-semidiluted $\left(\phi^{*}\right)$ and semidiluted-concentrated $\left(\phi^{* *}\right) \mathrm{CNC}$ particles suspended in water can be calculated using the rigid rod approximation:

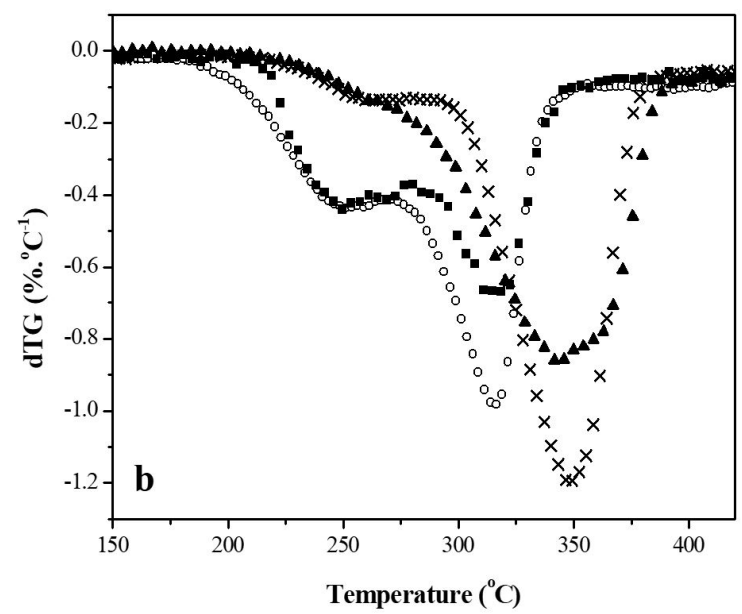

Figure 4. (a) TGA and (b) dTG curves for: CP ( $\Delta$ ), CNC-n (X), CNC-t (o) and CNF (•). 


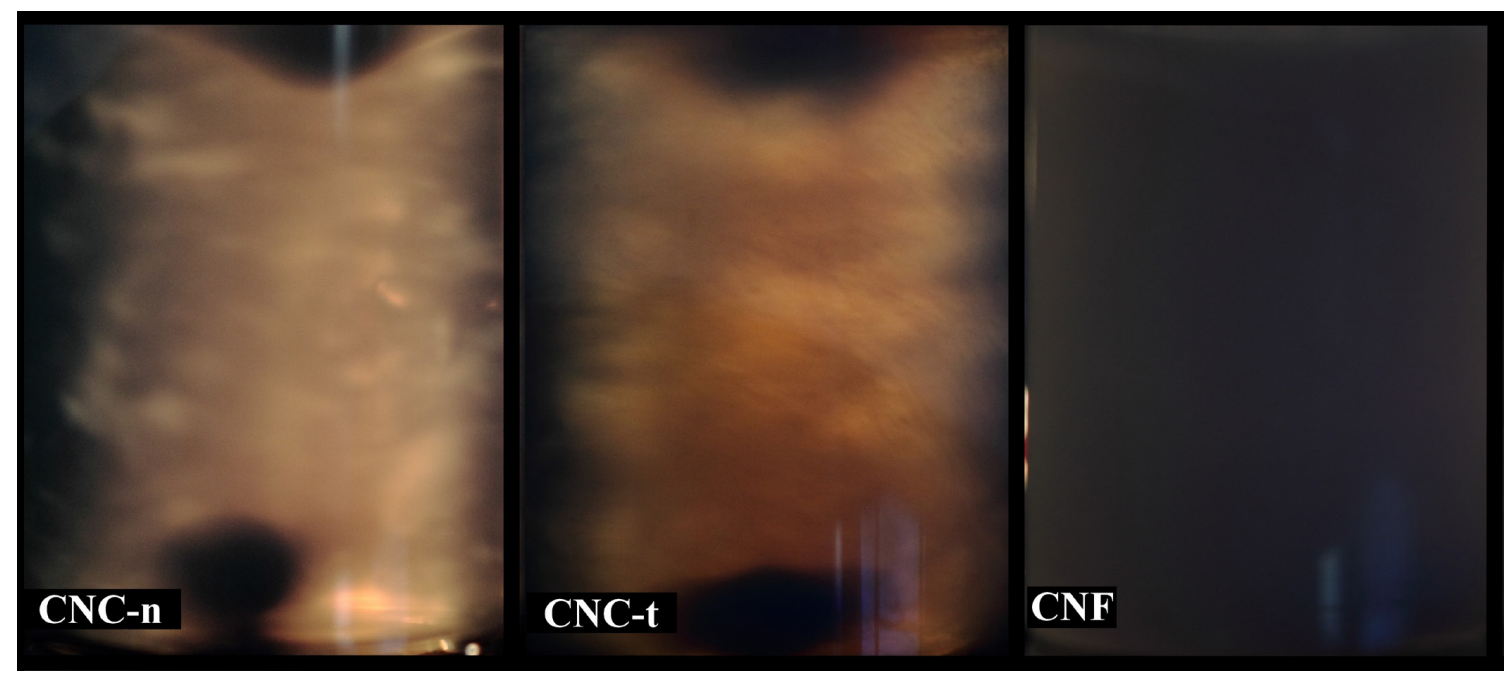

Figure 5. Birrefringence domaines of nanoparticle suspensions with concentration of $0.6 \mathrm{wt} \%$.

$$
\begin{aligned}
& \phi^{*}=\frac{d^{2}}{L^{2}} \\
& \phi^{* *}=\frac{d}{L}
\end{aligned}
$$

Equations 3 and 4 can show the transitions limits calculated from the particle dimentions, where $\mathrm{L}$ is the length and $\mathrm{d}$ the diameter of the particle. In our system, the particle dimentions lead to a diluted to semi-diluted regime transition around $0.0033 \mathrm{vol} \%$ (or $0.05 \mathrm{wt} \%$ ) and a semi-diluted to concentrated transition around $0.057 \mathrm{vol} \%$ (or $0.91 \mathrm{wt} \%$ ).

In this study, we choose to perform all the rheological measurements in the semidiluted regime where the samples are in an isotropic-at-rest regime and no anisotropy can be found. For CNF suspensions, the concentration was chosen to be the same as for the $\mathrm{CNC}$ suspensions in order to facilitate the discussion and data comparison. Figure 6 presents the evolution of the viscosity as a function of the shear rate. For all samples it is possible to observe a decrease in the viscosity value with shear rate increase (shear thinning behavior).

For the CNC samples, the viscosity value at lower shear rates is around $1 \mathrm{~Pa} . \mathrm{s}$, similar to values reported in the literature ${ }^{[27,28]}$. For CNC suspensions, the shear thinning behavior is normally explained by the progressive organization of the particles in suspension. At lower shear rates the nanocrystals are assumed to randomly organize. However the scenario starts to change with the shear rate increase and the rods are progressively align in the flow direction. This organization causes a decrease in the drag force, decreasing the viscosity value until a plateau. In this region, it is possible to observe an almost Newtonian flow behavior due to the maximum organization of the nanocrystals.

Besides the similar size and shape, CNC-n and CNC- $t$ viscosity curves shows some slight differences. The viscosity for the CNC-n suspension is higher at lower shear rates and this sample reaches the Newtonian plateau before CNC-t.

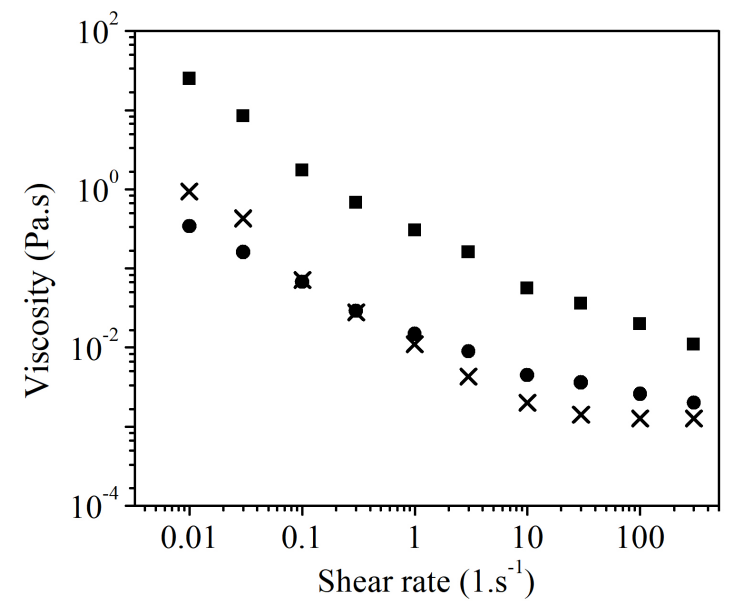

Figure 6. Steady-state viscosity versus shear rate for CNF (•), CNC-n (X) and CNC-t $(\bullet)$ suspensions with concentration of $0.6 \mathrm{wt} \%$.

Probably this behavior is caused by the differences in the nanocrystal surface chemistry.

For the CNF suspension, the viscosity values are significantly higher than for $\mathrm{CNC}$ at lower shear rate values, being around $30 \mathrm{~Pa} . \mathrm{s}$. This value is also similar to previous data reported in literature ${ }^{[1,26]}$. The shear thinning behavior is even more accentuated in this system. As a diluted sample, it is not possible to observe an intermediary plateau that is described by some authors with the concentration increase. Concerning the flow kinetics and the microstructureof this system under shear, it seems to be much more complicated than for the CNF system. Inhomogeneous flow is caused by erratic mesostructural changes. Floculation, fiber entanglement and wall slippage are phenomena present in this system due to the particles characteristics, i.e. size polidispersity, flexibility and surface charge ${ }^{[26,29]}$. 


\subsection{Oscillation measurements}

The rheological behavior of the particle dispersions was also characterized by dynamic oscillatory measurements. The intrinsic difference between the nanorods and the nanofibers was very clear even during the oscillation strain sweeps were the CNC samples showed a critical strain around $0.5 \%$, a much higher value than for CNF, which showed a critical strain around $0.025 \%$. The evolution of the values of G' and G' as afunction of angular frequency is ploted in Figure 7.

Cellulose nanomaterials are known for the possibility for form gels. These structures can be applied in different areas due to their great capacity to retain water and, still, behave as a solid. The "gel" state is defined by rheology as a suspension state where it presents a storage modulus (G') much higher than its loss modulus (G'), i.e. G' >> G'.

The storage modulus values can be regarded as the suspension ability to restore energy, and therefore, as the gel strength of the suspensions. In this study, all the samples presents gel-like behavior with G' values higher than G'. However, the ratio between $\mathrm{G}^{\prime}$ ' and G' (called $\tan \delta$ ) is greater than 0.1 for all studied samples until intermediary angular frequencies $\left(\mathrm{F}_{\mathrm{q}}\right)$. This means that the samples are not true gels, but can be considered as weak gels ${ }^{[30]}$, what is reasonable considering their low concentrations. This denomination is corroborated by the dependence of G' with $F_{q}$, since very stiff $\mathrm{CNC}$ gels (arising from more concentrated CNCs suspensions) do not present this dependence, presenting an almost constant $G^{\prime}$ value ${ }^{[31,32]}$.

For the nanorod samples, the weak gel behavior is very clear until $\mathrm{F}_{\mathrm{q}}$ values closer to $1 \mathrm{rad} \cdot \mathrm{s}^{-1}$. After this $\mathrm{F}_{\mathrm{q}}$ the values of loss and storage moduli start to be very similar (i.e. $\tan \delta$ is close to 1) and increase. This behavior is also described by Karppinen ${ }^{[33]}$ and $\mathrm{Wu}$ et al. ${ }^{[34]}$ for diluted nanocellulose (fibers and rods) suspensions. The first one considers it as a consequence of the concentration proximity with the threshold concentration for gel-like behavior ${ }^{[33,34]}$. However, this phenomenon seems to be more complex.

In this study, the G' and G" valuesfor diluted suspensions start to increase and became similar at intermediary $\mathrm{F}_{\mathrm{q}}$. This behavior is described by Ewoldt et al. ${ }^{[35]}$ as a consequence of inertial forces that can cause interferences in the measurements. It seems to be explained by the Reynolds number, Equation 5.

$$
\operatorname{Re}=\frac{\rho . v \cdot e}{\eta} \sim \frac{\text { InertialForces }}{\text { ViscousForces }}
$$

Where: $\rho$ is the fluid viscosity, $v$ is the fluid medium speed and $\mathrm{e}$ is the characteristic length of the flow process being considered (i.e. the rheometer plates gap in our case) and $\eta$ the fluid viscosity.
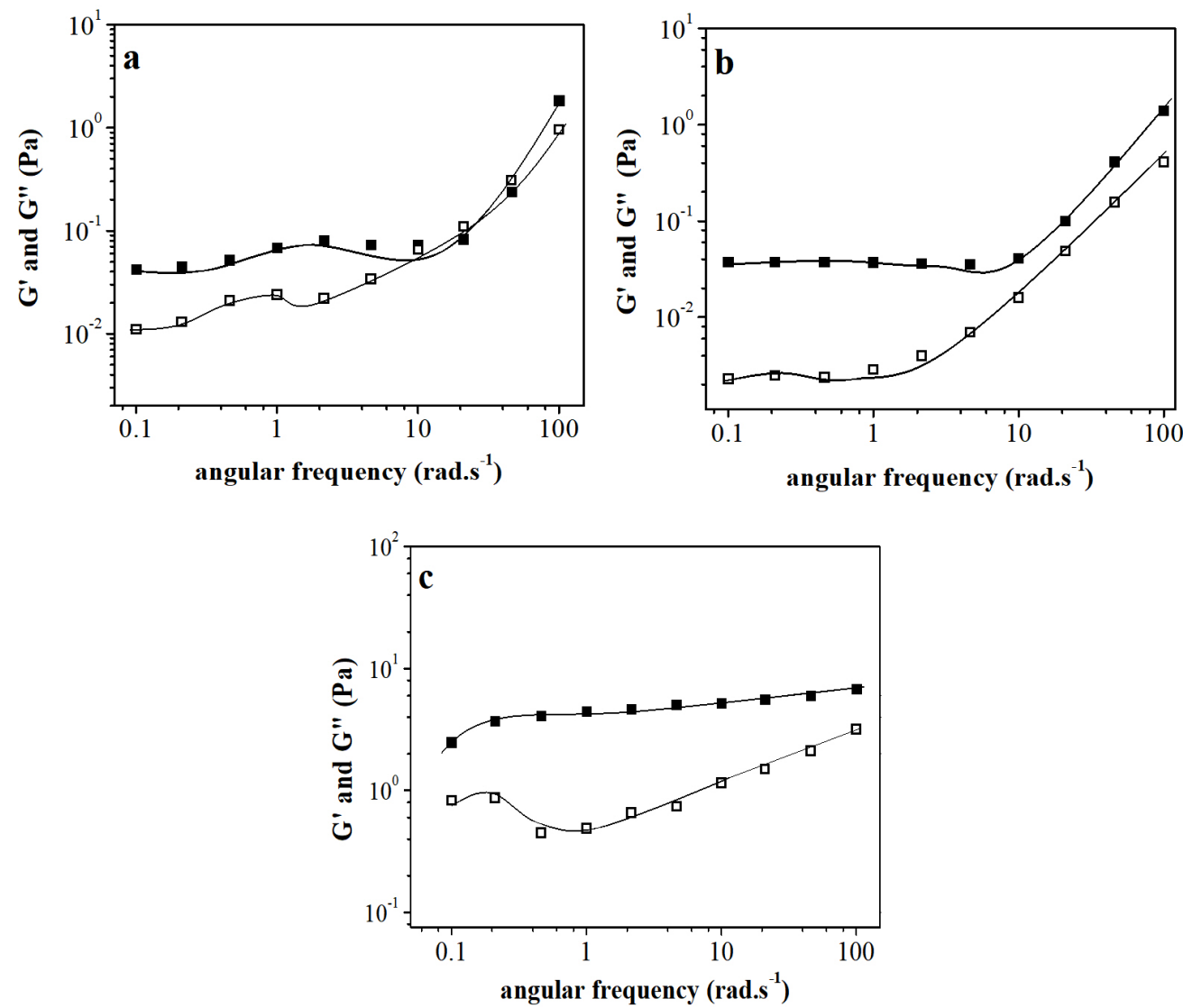

Figure 7. Storage, G' (solid symbols) and loss, G" (empty symbols) moduli as a function of oscilation frequency for (a) CNC-t, (b) CNC-n and (c) CNF. 
This equation illustrates the relationship between inertial and viscous forces. When the fluid presents low viscosity or flow values, the inertial effect can be negligible due to a compensation between both forces. However, in the case of systems with very low viscosity and/or high flow values, these effects begin to be representative and can influence the measurements, leading to false data. It is possible to observe in Figures 7a and 7b an increase in G' and G" at higher frequency values. Probably it occurs because inertial effects are causing a stress that is measured by the equipment. After a critical frequency it begins to distort and the obtained modulus values and G' and G" seems to grow.

This critical frequence $\left(\mathrm{F}_{\mathrm{qc}}\right)$ is a limit after which it is not possible to neglect inertial distortions in the obtained data. Equations 6 and 7 were suggested by Baravian (2013) and can provide quantitative information about this frequency due to inercial effects of fluid and equipment respectively ${ }^{[36]}$.

$$
\begin{aligned}
F_{q c} & <\frac{\eta}{\rho \cdot e^{2}} \\
F_{q c} & <\frac{\sqrt{G^{\prime} / \alpha}}{2 \pi}
\end{aligned}
$$

Where: (Equation 6) $\mathrm{F}_{\mathrm{qc}}$ is the critical frequence (in $\mathrm{Hz}$ ), $\eta$ is the viscosity values at $1 \mathrm{~Hz}$ frequency, $\rho$ is the suspension density, e is the plates gap distance; (Equation 7) $\alpha$ is a 0.05 coeficient for standard geometries and $\mathrm{G}$ ' is the modulus values at low frequencies. The respective obtained values for the studied suspensions are collected in Table 3.

For $\mathrm{CNC}$ samples, $\mathrm{F}_{\mathrm{qc}}$ is quite similar, considering the fluid and equipment inertial effects. It means that most of the frequency range for the $\mathrm{CNC}$ suspension at this concentration is under influence of inertial effects. The inertial effect from the rheometer seems to arise at lower frequencies if compared to the fluid effects for all the samples. According to Baravian, above $\mathrm{F}_{\mathrm{qc}}$ the rheometer error can be higher than $20 \%{ }^{[36]}$.

Since thes effects are viscosity-dependent, they are much less observable for $\mathrm{CNF}$ in the studied $\mathrm{F}_{\mathrm{q}}$ range. This sample present higher viscosity values, the fluid inertial effects only become significant after $92.4 \mathrm{rad} . \mathrm{s}^{-1}$ and probably shows most visibly distorted data at higher frequencies.

For lower $\mathrm{F}_{\mathrm{q}}$, where no inertial effects are affecting the data, the magnitude of the modulus values are clearly different between $\mathrm{CNC}$ an CNF samples, being much superior for the nanofibril suspension. It suggests that nanofibrils could create a stronger fibrous network at this concentration. In this suspension G' value is higher than G" over the whole studied frequency range and a relative weak influence of the frequency was found, a typical behavior of weak gels ${ }^{[32]}$.

Table 3. Samples viscosity and inertial critical frequencies.

\begin{tabular}{cccccc}
\hline \multirow{2}{*}{ Sample } & \multicolumn{2}{c}{ Fluid Inertia } & & \multicolumn{2}{c}{ Equipment Inertia } \\
\cline { 2 - 3 } \cline { 6 - 6 } & $\begin{array}{c}\text { Viscosity } \\
(\mathbf{m P a . s})\end{array}$ & $\begin{array}{c}\mathbf{F}_{\mathbf{q c}} \\
\left(\mathbf{r a d . s}^{-1}\right)\end{array}$ & & $\begin{array}{c}\mathbf{G} \\
(\mathbf{m P a})\end{array}$ & $\begin{array}{c}\mathbf{F}_{\mathbf{q c}} \\
\left.\text { (rad.s }^{-1}\right)\end{array}$ \\
\hline MNC-t & 2.1 & 3.6 & & 47 & 0.96 \\
MNC-n & 1.7 & 2.96 & & 35 & 0.83 \\
CNF & 53.0 & 92.4 & & 3800 & 8.71 \\
\hline
\end{tabular}

\section{Conclusions}

The aim of this study was to show how different properties can be obtained from the same cellulose source due to the versatility of this material. By controlling the size/shape of the particle and its surface charge and composition it was possible to modify its thermal and rheological characteristics.

The presence of charged groups for CNCs seems to be a key parameter that induces their earlier degradation during heating, an important drawback for composite processing by extrusion or injection. The particle dimentions seem to be responsible for significant modifications in the rheological parameters, such as viscosity and modulus of the nanoparticle suspensions in water. Also, we propose that diluted nanocellulose suspensions measurements can be highly influenced by inertial effects after a critical frequency, leading to false data obtainment. These effects also seem to be dependent of the sample dimensions, being more pronounced for $\mathrm{CNC}$ in the studied concentration and frequency range.

\section{Acknowledgements}

The authors gratefully acknowledge the Brazilian National Council for Scientific and Technological Development (CNPq) and "Ciência Sem Fronteiras" (CsF) program for the financial support (PhD fellowship of M.M.). LGP2 and LRP are part of the LabEx Tec 21 (Investissements d'Avenir - grant agreement $\mathrm{n}^{\circ}$ ANR-11-LABX-0030) and of the PolyNat Carnot Institut (Investissementsd' Avenir - grant agreement $\mathrm{n}^{\circ}$ ANR-16-CARN-0025-01). This research was made possible thanks to the facilities of the TekLiCell platform funded by the Région Rhône-Alpes (ERDF: European regional development fund).

\section{References}

1. Castro, D. O., Frollini, E., Marini, J., \& Ruvolo-Filho, A. C. (2013). Preparação e caracterização de biocompósitos baseados em fibra de curauá, Biopolietilenode Alta Densidade (BPEAD) e Polibutadieno Líquido Hidroxilado (PBHL). Polímeros. Ciência e Tecnologia, 23(1), 65-73.

2. Martins, M. A., \& Mattoso, L. H. C. (2003). Short sisal fiberreinforced tire rubber composites: dynamic and mechanical properties. Journal of Applied Polymer Science, 91(1), 670677. http://dx.doi.org/10.1002/app.13210.

3. Müller, C. M. O., Laurindo, J. B., \& Yamashita, F. (2009). Effect of cellulose fibers addition on the mechanical properties and water vapor barrier of starch-based films. Food Hydrocolloids, 23(5), 1328-1333. http://dx.doi.org/10.1016/j.foodhyd.2008.09.002.

4. Kalia, S., Kaith, B. S., \& Kaur, I. (2009). Pretreatments of natural fibers and their application as reinforcing material in polymer composites - a review. Polymer Engineering and Science, 49(7), 1253-1272. http://dx.doi.org/10.1002/ pen.21328.

5. Dufresne, A., \& Belgacem, M. N. (2013). Cellulose-reinforced composites: from micro-to nanoscale. Polímeros: Ciência e Tecnologia, 23(3), 277-286.

6. Sehaqui, H., Zhou, Q., Ikkala, O., \& Berglund, L. (2011). Strong and tough cellulose nanopaper with high specific surface 
area and porosity. Biomacromolecules, 12(10), 3638-3644. PMid:21888417. http://dx.doi.org/10.1021/bm2008907.

7. Abe, K., \& Yano, H. (2011). Formation of hydrogels from cellulose nanofibers. Carbohydrate Polymers, 85(4), 733-737. http://dx.doi.org/10.1016/j.carbpol.2011.03.028.

8. Castro, D. O., Frollini, E., Ruvolo, A. C. Fo., \& Dufresne, A. (2014). 'Green Polyethylene' and curaua cellulose nanocrystal based nanocomposites: effect of vegetable oils as coupling agent and processing technique. Journal of Polymer Science. Part B, Polymer Physics, 53(14), 1010-1019. http://dx.doi. org/10.1002/polb.23729.

9. Hoeng, F., Denneulin, A., Neuman, C., \& Bras, J. (2015). Charge density modification of carboxylated cellulose nanocrystals for stable silver nanoparticles suspension preparation. Journal of Nanoparticle Research, 17(6), 1-14. http://dx.doi.org/10.1007/ s11051-015-3044-z.

10. Lin, N., \& Dufresne, A. (2014). Nanocellulose in biomedicine: current status and future prospect. European Polymer Journal, 59,302-325. http://dx.doi.org/10.1016/j.eurpolymj.2014.07.025.

11. Nechyporchuk, O., Belgacem, M. N., \& Pignon, F. (2014). Rheological properties of micro-/nanofibrillated cellulose suspensions: wall-slip and shear banding phenomena Carbohydrate Polymers, 112, 432-439. PMid:25129764. http://dx.doi.org/10.1016/j.carbpol.2014.05.092.

12. Sun, W. L., Ye, W. F., \& Tao, W. Y. (2013). Improving enzymatic hydrolysis of cellulose from rice straw using an ionic liquid [EMIM]Ac pretreatment. Energy Sources. Part A, Recovery, Utilization, and Environmental Effects, 35(21), 2042-2050. http://dx.doi.org/10.1080/15567036.2010.532192.

13. Teodoro, K. B. R., Teixeira, E. M., Corrêa, A. C., Campos, A., Marconcini, J., \& Mattoso, L. H. C. (2011). Whiskers de fibra de sisal obtidos sob diferentes condições de hidrólise ácida: efeito do tempo e da temperatura de extração. Polímeros: Ciência e Tecnologia, 21(4), 280-285.

14. Siqueira, G., Abdillahi, H., Bras, J., \& Dufresne, A. (2010). High reinforcing capability cellulose nanocrystals extracted from syngonanthus nitens (Capim Dourado). Cellulose (London, England), 17(2), 289-298. http://dx.doi.org/10.1007/s10570009-9384-z.

15. Silvério, H. A., Flauzino, W. P. No, Silva, I. S. V., Rosa, J. R., Pasquini, D., Assunção, R. M. N., Barud, H. D. S., \& Ribeiro, S. J. L. (2014). Mechanical, thermal, and barrier properties of methylcellulose/cellulose nanocrystals nanocomposites. Polímeros: Ciência e Tecnologia, 24(6), 683-688.

16. Lin, N., \& Dufresne, A. (2013). Physical and/or chemical compatibilization of extruded cellulose nanocrystal reinforced polystyrene nanocomposites. Macromolecules, 46(14), 55705583. http://dx.doi.org/10.1021/ma4010154.

17. Wang, N., Ding, E., \& Cheng, R. (2007). Thermal degradation behaviors of spherical cellulose nanocrystals with sulfate groups. Polymer, 48(12), 3486-3493. http://dx.doi.org/10.1016/j. polymer.2007.03.062

18. Nooy, A. E. J., Besemer, A. C., \& Bekkum, H. (1995). Highly selective nitroxyl radical-mediated oxidation of primary alcohol groups in water-soluble glucans. Carbohydrate Research, 269(1), 89-98. http://dx.doi.org/10.1016/0008-6215(94)00343-E.

19. Beck-Candanedo, S., Roman, M., \& Gray, D. G. (2005). Effect of reaction conditions on the properties and behavior of wood cellulose nanocrystal suspensions. Biomacromolecules, 6(2), 1048-1054. PMid:15762677. http://dx.doi.org/10.1021/ bm049300p.
20. Roman, M., \& Winter, W. T. (2004). Effect of sulfate groups from sulfuric acid hydrolysis on the thermal degradation behavior of bacterial cellulose. Biomacromolecules, 5(5), 1671-1677. PMid:15360274. http://dx.doi.org/10.1021/bm034519+.

21. Alvarez, V. A., \& Vázquez, A. (2004). Thermal degradation of cellulose derivatives/starch blends and sisal fibre biocomposites. Polymer Degradation \& Stability, 84(1), 13-21. http://dx.doi. org/10.1016/j.polymdegradstab.2003.09.003.

22. Samir, M. A. S. A., Alloin, F., \& Dufresne, A. (2005). Review of recent research into cellulosic whiskers, their properties and their application in nanocomposite field. Biomacromolecules, 6(2), 612-626. PMid:15762621. http://dx.doi.org/10.1021/ bm0493685.

23. Lin, N., \& Dufresne, A. (2014). Surface chemistry, morphologica analysis and properties of cellulose nanocrystals with gradiented sulfation degrees. Nanoscale, 6(10), 5384-5393. PMid:24706023. http://dx.doi.org/10.1039/C3NR06761K.

24. Matsuoka, S., Kawamoto, H., \& Saka, S. (2014). What is active cellulose in pyrolysis? An approach based on reactivity of cellulose reducing end. Journal of Analytical and Applied Pyrolysis, 106, 138-146. http://dx.doi.org/10.1016/j.jaap.2014.01.011.

25. Shoji, T., Kawamoto, H., \& Saka, S. (2014). Boiling point of levoglucosan and devolatilization temperatures in cellulose pyrolysis measured at different heating area temperatures. Journal of Analytical and Applied Pyrolysis, 109, 185-195. http://dx.doi.org/10.1016/j.jaap.2014.06.014.

26. Karppinen, A., Saarinen, T., Salmela, J., Laukkanen, A., Nuopponen, M., \& Seppälä, J. (2012). Flocculation of microfibrillated cellulose in shear flow. Cellulose (London, England), 19(6), 1807-1819. http://dx.doi.org/10.1007/s10570012-9766-5.

27. Bercea, M., \& Navard, P. (2000). Shear dynamics of aqueous suspensions of cellulose whiskers. Macromolecules, 33(16), 6011-6016. http://dx.doi.org/10.1021/ma000417p.

28. Ureña-Benavides, E. E., Brown, P. J., \& Kitchens, C. L. (2010). Effect of jet stretch and particle load on cellulose nanocrystalalginate nanocomposite fibers. Langmuir, 26(17), 14263-14270. PMid:20712357. http://dx.doi.org/10.1021/la102216v.

29. Martoïa, F., Perge, C., Dumont, P. J. J., Orgéas, L., Fardin, M., Manneville, S., \& Belgacem, M. N. (2015). Heterogeneous flow kinematics of cellulose nanofibril suspensions under shear. Soft Matter, 11(24), 4742-4755. PMid:25892568. http:// dx.doi.org/10.1039/C5SM00530B.

30. Pereira, E. A., Brandão, E. M., Borges, S. V., \& Maia, M. C. A. (2008). Influence of concentration on the steady and oscillatory shear behavior of umbu pulp. Revista Brasileira de Engenharia Agricola e Ambiental, 12(21), 87-90. http:// dx.doi.org/10.1590/S1415-43662008000100013.

31. Ureña-Benavides, E. E., Ao, G., Davis, V. A., \& Kitchens, C. L. (2011). Rheology and phase behavior of lyotropic cellulose nanocrystal suspensions. Macromolecules, 44(22), 8990-8998. http://dx.doi.org/10.1021/ma201649f.

32. Tzoumaki, M. V., Moschakis, T., \& Biliaderis, C. G. (2013). Effect of soluble polysaccharides addition on rheological properties and microstructure of chitin nanocrystal aqueous dispersions. Carbohydrate Polymers, 95(1), 324-331. PMid:23618276. http://dx.doi.org/10.1016/j.carbpol.2013.02.066.

33. Karppinen, A. (2014). Rheology and flocculation of polymermodified microfibrillated cellulose suspensions. Finland: Aalto University.

34. Wu, Q., Meng, Y., Wang, S., Li, Y., Fu, S., Ma, L., \& Harper, D. (2014). Rheological behavior of cellulose nanocrystal 
suspension: Influence of concentration and aspect ratio. Journal of Applied Polymer Science, 131(15), 1-8. http:// dx.doi.org/10.1002/app.40525.

35. Ewoldt, R. H., Johnston, M. T., \& Caretta, L. M. (2015). Experimental challenges of shear rheology: how to avoid bad data. In S. Spagnolie (Ed.), Complex fluids in biological systems (1st ed., pp. 207-241). New York: Springer-Verlag. http://dx.doi.org/10.1007/978-1-4939-2065-5.
36. Baravian, C. (2013). Effets inertiels en rhéométrie instationnaie. In J. L. Grossiord, \& A. Ponton (Eds.), La mesure en rhéologie: des avancées récentes aux perspectives (pp. 31-48). France: EDP Sciences.

Received: Nov. 09, 2015

Revised: Apr. 01, 2016

Accepted: Apr. 13, 2016 